REVIEW

\title{
GH replacement therapy in elderly GH-deficient patients: a systematic review
}

\author{
Nieke E Kokshoorn, Nienke R Biermasz, Ferdinand Roelfsema, Johannes W A Smit, Alberto M Pereira \\ and Johannes A Romijn \\ Department of Endocrinology and Metabolic Diseases C4-R, Leiden University Medical Center, PO Box 9600, 2300 RC Leiden, The Netherlands \\ (Correspondence should be addressed to N E Kokshoorn; Email: n.e.kokshoorn@lumc.nl)
}

\begin{abstract}
Context: Recombinant human GH (rhGH) is prescribed for the treatment of adults with GH deficiency (GHD). However, conflicting data are available on the efficacy of rhGH treatment in elderly GHD patients.

Objective: To assess the efficacy of rhGH treatment in elderly GHD subjects.

Methods: We searched the available literature in PubMed, Cochrane Library, Web of Science and EMBASE. Study selection: Studies on GHD patients, aged $>60$ years, treated with rhGH were eligible for inclusion. Data extraction was performed by two reviewers independently.

Results: We found 11 eligible studies with a total of 534 patients. Only two studies had prospective, randomized, placebo-controlled study designs of rhGH treatment with a duration of $6(n=15)$ and 12 months $(n=62)$, respectively. Treatment with rhGH decreased total and low density lipoprotein (LDL) cholesterol levels by $4-8$ and $11-16 \%$, respectively, but did not alter high density lipoprotein or triglyceride levels. RhGH did not affect body mass index, but decreased waist circumference (by $\sim 3 \mathrm{~cm}$ ) and waist/hip ratio. RhGh did not consistently affect blood pressure or bone mineral density. RhGH increased lean body mass by $2-5 \%$ and decreased total fat mass by $7-10 \%$ in four studies, but did not affect body composition in two other studies. RhGH consistently improved quality of life (QoL) parameters reflected in AGHDA-scores. There were no explicit data on elderly GHD patients aged $>80$ years. Conclusion: RhGH replacement in elderly subjects with GHD decreases LDL cholesterol levels and improves QoL, but the effects on other parameters are not unequivocal. There were no data on the efficacy and safety of rhGH treatment in octogenarians with GHD.
\end{abstract}

European Journal of Endocrinology 164 657-665

\section{Introduction}

In healthy adults, GH secretion declines with increasing age $(1,2)$. Some of the clinical features of normal aging resemble the manifestations of pathological GH deficiency (GHD). These features include changes in body composition (BC), such as increased total fat mass, decreased lean body mass (LBM) and decreased bone mass, as well as a higher prevalence of cardiovascular risk factors and diminished cardiac function (3).

Consequently, a number of studies have examined the effect of recombinant human $\mathrm{GH}$ (rhGH) on various clinical parameters in otherwise healthy elderly subjects (4) as well as in elderly patients with GHD. Rudman et al. (5) were the first to report that 6 months of rhGH treatment in healthy elderly men reduced adiposity and increased muscle mass and bone mineral density (BMD). Other studies observed similar beneficial effects, suggesting a potential role for rhGH as anti-aging therapy (6-8). A recent systematic review and meta-analysis of randomized controlled trials observed that rhGH treatment decreased overall fat mass decreased by $\sim 2.1 \mathrm{~kg}$ and increased overall LBM increased by $\sim 2.1 \mathrm{~kg}$ (CI, 1.3-2.9) $(P<0.001)$, without any effect on weight. However, rhGH was associated with increased rates of adverse effects (4). Moreover, in healthy elderly subjects, higher physiological insulinlike growth factor 1 (IGF1) concentrations are associated with increased mortality (9).

Several studies assessed the clinical benefits of rhGH therapy in elderly GHD patients. Some studies in elderly patients with GHD documented that, rhGH improved quality of life (QoL) $(10,11), \mathrm{BC}(12-14)$ and lipoprotein profiles $(11,15,16)$, although another study showed no effects (17). A consensus statement on the treatment of GHD adults states that 'the age-related decline in the GH-IGF1 status does not warrant rhGH supplementation, but patients with proven GHD should be treated'. These guidelines indicate that the dose of rhGH should be adjusted with advancing age, because of the normal age-related decline in GH secretion (18). Apparently, there is no clear age limitation in treating elderly GHD adults with rhGH. 
The aim of the present study was to critically assess the available literature in order to evaluate the available evidence for treatments of elderly patients with GHD. Therefore, we performed a structured review of the available literature on this subject.

\section{Subjects and methods}

\section{Search strategy}

We performed a systematic search in the following databases: PubMed, EMBASE, Web of Science, Cochrane Library, CINAHL database and Academic Search Premier. The search strategy included three main issues: GHD, age $>60$ years and GH replacement therapy. We used all relevant keyword variations, including free text words. This resulted in the following search string: (("Growth hormone deficiency"[ti] OR "Growth Hormone/deficiency"[Majr] OR "GH deficien$c y$ "[ti] OR "Growth hormone deficient"[ti] OR "GH deficient"[ti] OR GHD[ti]) AND ("aged"[Mesh] OR elderly[tw] OR oldest old OR Nonagenarians OR Nonagenarian $O R$ septuagenarian $O R$ septuagenarians OR Octogenarians OR Octogenarian OR Centenarians OR Centenarian)) OR (("Growth hormone deficiency"[ti] OR "Growth Hormone/deficiency"[Majr] OR "GH deficien$c y$ "[ti] OR "Growth hormone deficient"[ti] OR "GH deficient"[ti] OR GHD[ti] OR "Growth hormone deficiency" OR "growth hormone deficient" OR "gh deficiency" OR "gh deficient") AND ("Growth Hormone/administration and dosage"[Mesh] OR "GH/therapeutic use"[Mesh] OR "Growth Hormone/therapy"[Mesh] OR ((growth hormone OR growth hormones OR Somatotropin OR Somatotropins) AND (therapy OR therapeutic OR replacement))) AND ("aged"[mesh] OR elderly[tw] OR oldest old OR Nonagenarians OR Nonagenarian OR septuagenarian OR septuagenarians OR Octogenarians OR Octogenarian OR Centenarians OR Centenarian))) AND (English[lang]. Furthermore, the references of relevant articles were checked for additional articles. The following exclusion criteria were used: age $<60$ year, non-GHD subjects and no rhGH therapy.

\section{Data review}

The following data were extracted from each study: i) age, gender and number of patients, ii) the endocrine tests used to diagnose GHD, iii) criteria used to define GHD, iv) duration of treatment and treatment dose and v) the effect of GH on individual outcome parameters.

\section{Results}

The initial search resulted in a total of 577 articles (527 in PubMed, 3 in Cochrane Library, 15 in Web of Science and 26 in EMBASE, O CINAHL database and
6 Academic Search Premier). Of these 577 articles, 534 were unique without duplications. We excluded 403 papers based on title and abstract (studies on GHD without specific focus on rhGH replacement therapy and/or age $<60$ years $(n=326)$ and reviews $(n=77))$. In 89 additional papers, which included patients with an age $>60$ years, the individual data of the patients could not be extracted. Two additional papers were not available for evaluation.

Therefore, a total of 40 potentially relevant manuscripts were retrieved for full assessment, of which 26 studies were excluded from further analysis because those studies did not meet one or more of the eligibility criteria (age $<60$ years, no rhGH therapy and healthy elderly).

Ultimately, the search strategy resulted in a total of 14 manuscripts meeting our inclusion criteria. However, only eight different cohorts of patients were described in these 14 studies, because several studies described data from the same patient cohort. The studies by Götherström et al. $(12,19)$ described the same patient cohort $(n=24)$ after 5 and 10 years of rhGH treatment. The studies by Elzgyri et al. (16) and Fernholm et al. (13) $(n=31)$ as well as Gill et al. (14) and Toogood et al. (20) $(n=12)$ also described the same patient cohort. Therefore, the data of these studies are described in combination. $(12-14,16,19,20)$ The studies reported from the KIMS database included different numbers of patients in each publication ( $n=64, n=125, n=135, n=64)$. Although it is likely that similar patients have been included, the different numbers of subjects preclude combination of the data of these separate studies $(10,11,15,21)$.

Consequently, a total of 11 studies were included in the present review, comprising 534 patients (Fig. 1).

\section{Study designs}

Two studies $(n=65)$ had a prospective placebocontrolled, randomized design assessing the effects of rhGH treatment during $6(n=15)$ and $12(n=62)$ months, respectively, in elderly GHD patients $(16,17)$. The study by Elzgyri et al. (16), that evaluated the effects of rhGH versus placebo for 6 months, was continued for another 12 months using a nonrandomized prospective study design.

The other nine studies had a non-randomized prospective study design, in which the basal data prior to rhGH treatment were used to assess the effects of rhGH $(n=469)$. Four of these studies $(n=388)$ used patients derived from the KIMS database $(10,11,15,21)$.

In this review, we only included studies on patients above the age of 60 years. Two studies did not specify the age of the patient, but only indicate that all patients are $>60$ years $(10,11)$. One study assessed patients between the age 60 and 70 years (22), and in three 


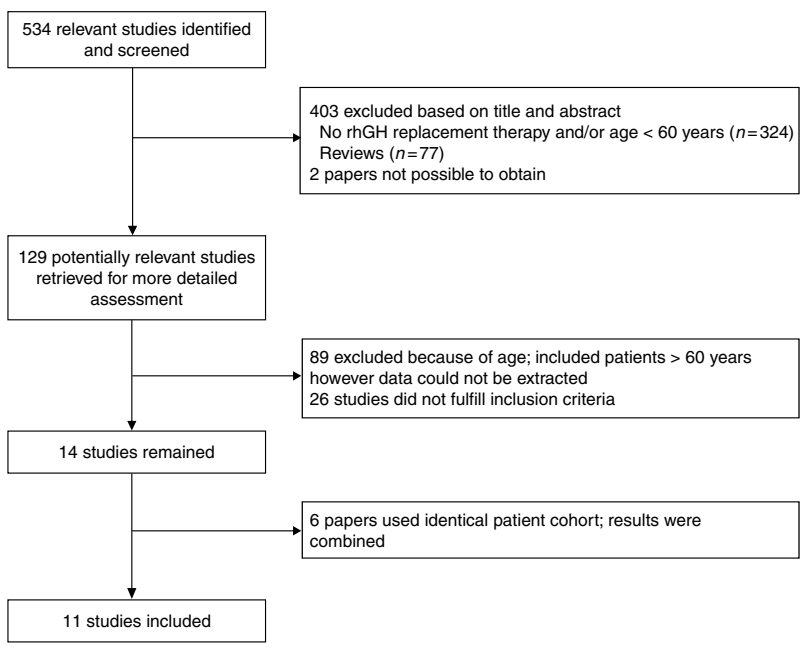

Figure 1 Summary of study assessment and exclusion stages.

studies, the age ranged between 60 and 75 years $(12$, 21,23 ). Five studies included patients $>75$ years and only two of these studies included patients with age $>80$ years $(14-17,24)$.

\section{Endocrine evaluation}

All 11 studies used stimulation tests for the evaluation of GH reserve (Table 1). Different tests, however, were used, including insulin tolerance test (ITT), combined GHRH plus arginine (GHRH + arginine) test, glucagon stimulation test or stimulation with arginine alone (Table 1). The ITT was used in the total population or in the majority of patients in seven studies $(11,12,15,17$, 21-23). The study by Koltowska et al. (10) did not mention which tests were used to diagnose GHD. However, that study also described patients from the KIMS database, and, therefore, it can be assumed that the ITT was also used in the majority of these patients. The remaining three studies either used GHRH tests (16), arginine tests (14) or combined GHRH+arginine tests (24). All but one study applied the generally used cut-off value for severe GHD of a peak GH $<3 \mu \mathrm{g} / \mathrm{l}$. In the study by De Marinis et al. (24), which used the $\mathrm{GHRH}+$ arginine test, severe GHD was defined as a GH peak $<15 \mu \mathrm{g} / \mathrm{l}$, without corrections for the effects of body mass index (BMI).

\section{Duration and dose of rhGH treatment}

The duration of treatment with rhGH ranged from 6 months $(n=15)$ to 10 years $(n=24)$. Six studies $(n=390)$ calculated the GH dose based on bodyweight $(11,12,15,16,21,24)$. One of these studies used a predefined dose per $\mathrm{kg}$ bodyweight per day $(0.0119 \mathrm{mg} / \mathrm{kg}$ per day) (12). The other five studies titrated the $\mathrm{rhGH}$ dose/kg per week $(0.017-$ $0.042 \mathrm{mg} / \mathrm{kg}$ per week) $(11,15,16,21,24)$.
Of the remaining five studies, one study gave three fixed doses of rhGH $(0.17,0.33$, and $0.5 \mathrm{mg} /$ day $)$ for 12 weeks. These patients received the highest dose of $\mathrm{rhGH}$, i.e. $0.5 \mathrm{mg} /$ day (14). In the remaining four studies, rhGH was titrated on an individual basis with the aim to reach IGF1 levels within the normal age- and sex-related range or clinical improvements, taking QoL and $\mathrm{BC}$ into account. The mean dose of rhGH ranged from 0.11 to $0.37 \mathrm{mg} /$ day $(11,15,21,24)$.

\section{IGF1 levels and S.D. scores}

Seven of the 11 studies used age-adjusted IGF1 levels measured in a control population to titrate rhGH dose (11, 12, 14, 16, 21-23). Götherström et al. (19) and Franco et al. (8) both used the same references values measured in a group of 392 patients aged between 25 and 64 years, as described by Landin-Wilhelmsen et al. (25). Feldt-Rasmussen et al. (11) and Monson et al. $(15,21)$ both refer to a study by Drake et al. $(26)$. However, that study does not mention the IGF1 reference values, but refers to a dose finding study by Janssen et al. (27), in which normative data were based on 54 healthy control subjects aged $20-70$ years. The study by Elzgyri et al. (16) used reference values derived from the study by Hilding et al. (28), in which IGF1 values were measured in a population of 448 healthy controls aged 20-96 years. The remaining two studies measured reference values in an own reference population of 450 (18-80 years) (22) and 124 (60-84 years) (14) healthy controls, respectively.

All studies titrated the rhGH dose with the aim of normalizing IGF1 s.D. scores, i.e. aiming at IGF1 SDS in physiological levels for age and sex (between -2 and +2 ). However, four studies also took the clinical response and $\mathrm{BC}$ into account for titration of the rhGH dose. Feldt-Rasmussen et al. (11) and Monson et al. (15) both took the clinical response into account when titrating rhGH dose, referring to a study by Drake et al. (26), in which waist/hip (W/H) measurements and improvement of QoL measured by AGHDA were taken into account for the titration of the dose. The remaining two studies $(12,23)$ both state that, when adjusting the rhGH dose, the aim is to 'normalizing IGF1 and BC...', both referring to a study by Johannssen et al. (7), in which individualized doses of rhGH are compared with doses based on body weight. In their study, normalization of $\mathrm{BC}$ was of great importance and normal values derived from a study by Bruce et al. (29), comprising 376 patients in the age $20-70$ years, were used to evaluate patients and adjust rhGH levels.

\section{Effects of rhGH on cardiovascular and metabolic parameters}

Nine studies $(n=460)$ assessed the effects of rhGH on cardiovascular risk factors $(11,12,14-17,21,23,24)$. Five studies $(n=424)$ assessed the effects on plasma 


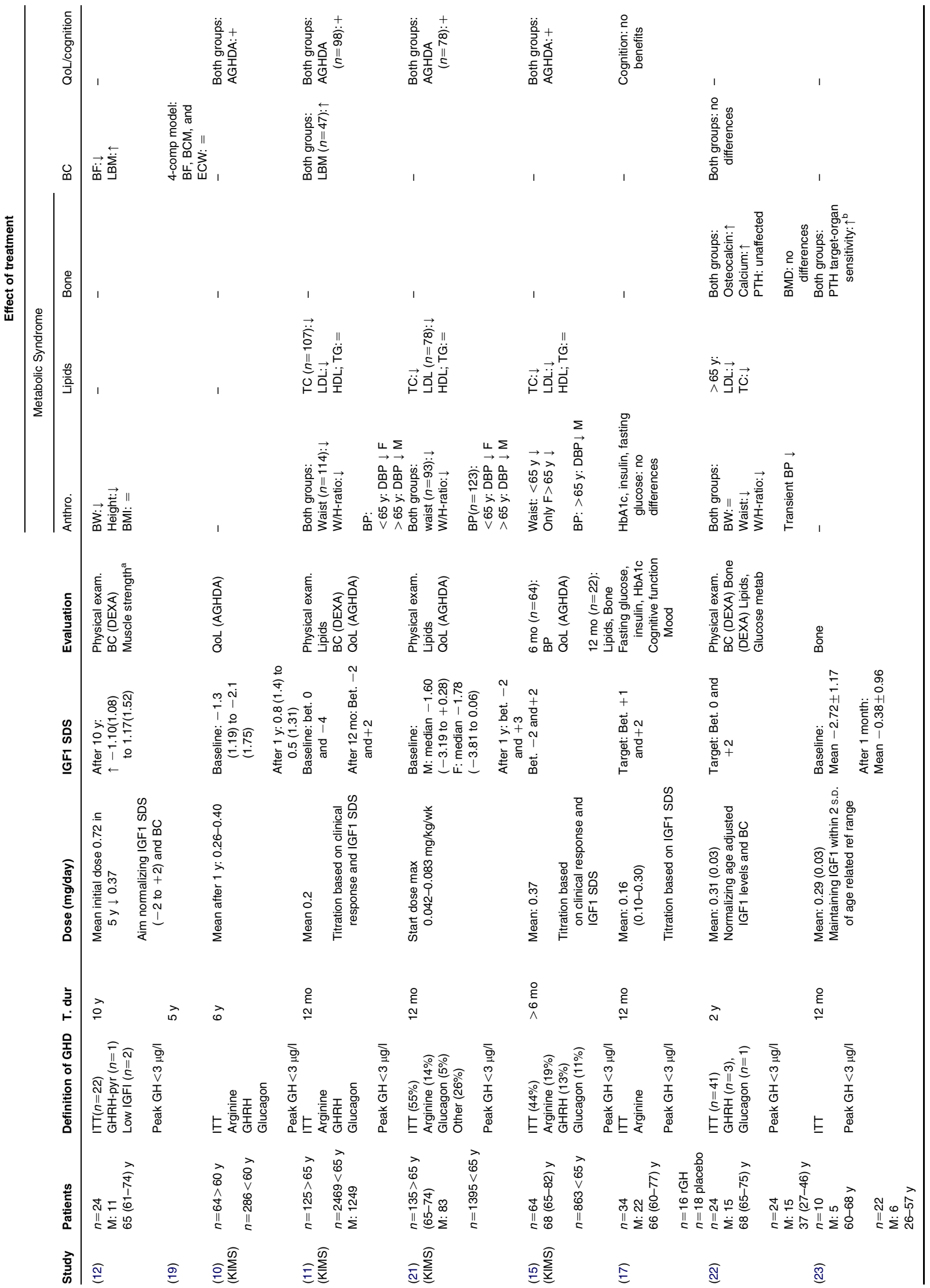




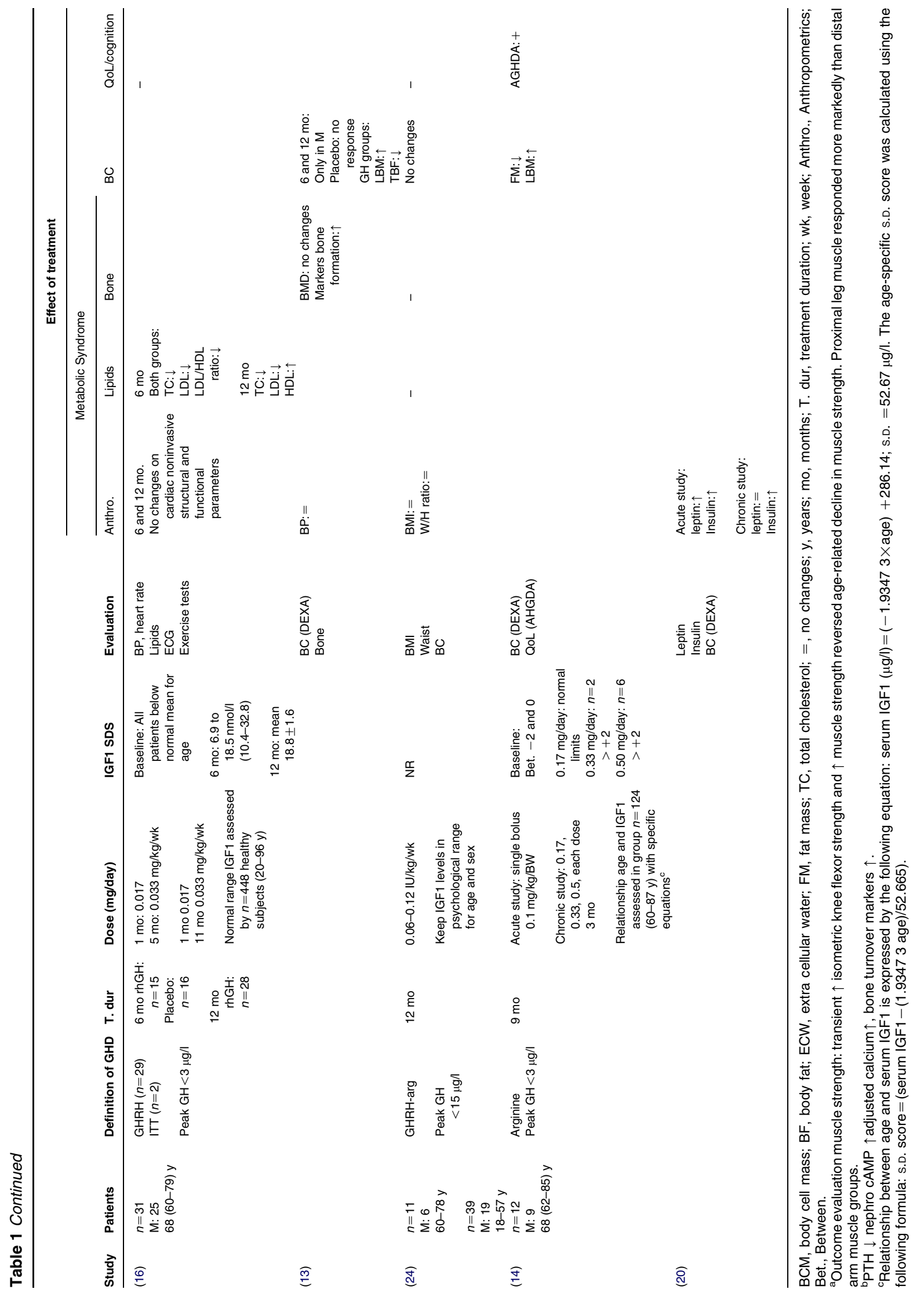

www.eje-online.org 
lipid profiles $(11,15,16,21,23)$. In general, rhGH treatment decreased total and low density lipoprotein (LDL) cholesterol levels by $4-8 \%(15,16,23)$ and by $11-16 \%$, respectively, whereas rhGH increased high density lipoprotein (HDL) only by $17 \%$ in one other study (16). Treatment with rhGH did not affect triglyceride (TG) levels at all.

Six studies assessed the effects of rhGH on body weight, height, BMI and/or W/H ratios $(11,12,15,21$, 23, 24). In two studies, rhGH did not affect BMI $(12,24)$. In three of five studies which reported $\mathrm{W} / \mathrm{H}$ ratios, there was a significant decrease in waist circumference $(3 \mathrm{~cm}$ in de study by Franco et al. 2006 (23)) and $\mathrm{W} / \mathrm{H}$ ratios $(11,15,21,23)$. However, the two other studies did not find any effect of rhGH on $\mathrm{W} / \mathrm{H}$ ratios $(15,24)$.

Five studies assessed the effects of rhGH on blood pressure (BP) $(n=379)(11,15,16,21,23)$. There were no clear consistent effects of rhGH treatment on BP. Treatment with rhGH did not affect (16), only transiently decreased BP (23), or decreased diastolic BP only $(11,15,21)$.

One study used an exercise test to evaluate cardiac function $(n=31)$. Treatment with rhGH induced a transient increase in heart rate at rest and exercise. However, rhGH treatment did not affect cardiac structural and functional parameters (16).

\section{Effects of rhGH on bone parameters}

The effects of rhGH therapy on bone metabolism were evaluated in three studies $(n=65)$. Treatment with rhGH did not affect BMD. One study found that treatment with rhGH increased osteocalcin and calcium levels without any change in PTH levels (23). Another study found that rhGH treatment lowered PTH and urinary cAMP levels, associated with higher adjusted calcium and bone turnover markers, indicating a higher PTH target organ sensitivity (22). The third study observed that treatment with rhGH induced higher markers for bone formation (bone-specific alkaline phosphatase activity, osteocalcin and procollagen I carboxyl-terminal peptide in serum) (13). The effects of rhGH treatment on fracture incidence were not described.

\section{Effects of rhGH on BC}

Six studies assessed the effects of rhGH on BC using DEXA scan $(n=138)(11,12,14,16,23,24)$. Two studies $(n=35)$ found no effect of rhGH on BC $(23,24)$. In contrast, the other four studies $(n=103)$ found that 6 months of rhGH treatment induced a significant increase in LBM by $2-5 \%$ and a significant decrease in total body fat by $7-10 \%(12,14,16)$. Moreover, these effects of rhGH on BC were reversed, when rhGH therapy was subsequently stopped $(n=12)$ (14). One study used a four-compartment model to assess body fat, body cell mass and extracellular weight, but these parameters were not affected by rhGH therapy $(12,19)$.

\section{Effects of rhGH on QoL and cognitive functioning}

The effects of rhGH treatment on QoL parameters was assessed using only the AGHDA questionnaire in five studies $(n=400)(10,11,14,15,21)$. The majority of these patients were from the KIMS database $(n=388)$. Treatment with rhGH induced significant improvements of AGHDA scores in all studies.

Only one study assessed cognitive functioning $(n=34)$ using computerized psychometric test package (Neurobehavioral Examination-System 2). However, compared with placebo, rhGH therapy was not associated with improvement in cognition after 12 months.

\section{Effects of rhGH on muscle strength}

One study assessed the effects of 5 and 10 years of rhGH treatment on muscle strength $(n=24)$ (12). Treatment with rhGH induced a transient improvement only in knee flexor strength. However, rhGH treatment protected from most of the normal age-related decline in muscle performance and neuromuscular function.

\section{Adverse effects}

Six of the 11 studies mention possible adverse effects of rhGH treatment. In two studies, the number of adverse events (AEs) was similar for younger and older patients with GHD (11, 15). However, younger patients appeared to have more AEs related to fluid retention (i.e. headaches, edema and arthralgias), whereas patients $>65$ years had more AEs related to glucose metabolism, cerebrovascular events and neoplasms (11). One of the two placebo-controlled studies mentioned AEs and found no differences between the placebo and rhGH groups (17).

In the study by Fernholm et al. (13), 25\% of the patients $(8 / 31)$ developed side effects, probably due to fluid retention (peripheral edema, joint stiffness and muscle pain). However, these side effects subsided spontaneously or after minor dose reduction. The study using the highest dose found AEs in three of the 12 patients. The AEs subsided when the dose was down titrated (20). One study needed to reduce the dose of rhGH because of symptoms of the carpal tunnel syndrome (22).

\section{Discussion}

This systematic literature review assessed the effects of rhGH treatment in elderly GHD patients. The data 
indicate unequivocally that rhGH treatment positively affects total and LDL cholesterol levels and QoL parameters. There is controversy on the effects of rhGH substitution on other cardiovascular risk factors, including insulin, HDL cholesterol, BP and BC, whereas rhGH therapy does not improve plasma triglyceride levels. Moreover, treatment with rhGH did not improve BMD in elderly subjects with GHD. Finally, studies on the effects of rhGH treatment in elderly GHD patients on clinically relevant endpoints, e.g. cardiovascular morbidity, fractures and mortality, have not been reported.

There is hardly any information on the treatment of very old GHD patients with rhGH. Although two studies included patients $>80$ years, data on these patients could not be extracted. Therefore, at present, there is no information with respect to the efficacy and safety of rhGH treatment in GHD octogenarians.

All patients described in the studies included in this systematic review were diagnosed with severe GHD, based on different endocrine stimulation tests. However, because of the decline in GH secretion during aging, it may have affected the cut-off values of the $\mathrm{GH}$ stimulation tests. Studies using the ITT have been performed in these patients with various results. A study by Finucane et al. (30) show that the ITT is a safe test even in elderly patients. However, other studies do show a lower GH response to ITT in the elderly (31). Nonetheless, the ITT is contraindicated in patients with cardiac ischemia or arrhythmias. There are discrepancies between the studies on the cut-off values of the combined GHRH + arginine test and of the arginine test. In previous studies, age seemed to be of no influence when using these tests $(32,33)$. However, there is a significantly lower peak GH response in elderly compared with younger patients in the GHRH + arginine test (34). Therefore, the omission to reduce the cut-off values of $\mathrm{GH}$ stimulation tests in aging subjects may result in an erroneous diagnosis of GHD in some of these subjects. The extent to which this may have affected the conclusions is uncertain, at present.

During aging, GH secretion decreases, associated with a decline in IGF1 levels. Therefore, age-adjusted IGF1 S.D. scores are necessary to be able to assess the treatment response to rhGH. All studies titrated the rhGH dose with the aim of normalizing IGF1 s.D. scores, i.e. aiming at IGF1 SDS in physiological levels for age and sex (between -2 and +2 ). However, from the analysis described in the results section, it becomes evident that, in some studies, S.D. scores were higher. In addition, some studies included the response of $\mathrm{BC}$ to titrate the rhGh dose. Finally, some studies used IGF1 scores from reference populations with a different age distribution. Therefore, there are methodological differences between the included studies, which may have affected the relation between physiological rhGH replacement and responses in elderly subjects.

In GHD elderly subjects, treatment with rhGH had undisputed positive effects on total and LDL cholesterol levels, and on QoL $(10,11,14,15,21)$. Treatment with rhGH decreased total and LDL cholesterol levels by 4-8 and $11-18 \%$, respectively. However, the translation of the consistent benefits of rhGh on LDL cholesterol in terms of clinical outcomes is difficult to assess. For instance, it is uncertain whether the beneficial effects induced by rhGH on LDL cholesterol levels will ultimately translate into decreased cardiovascular morbidity and mortality. The effects of changes in this cardiovascular risk factor are not as evident as in younger patients. For instance, in the PROSPER trial, which assessed the effects of primary intervention with pravastatin in elderly subjects with a history of, or risk factors for, vascular disease, baseline LDL cholesterol showed no relation to risk of the primary cardiovascular endpoint in the placebo group, nor did on-treatment LDL cholesterol in the pravastatin group (35).

$\mathrm{RhGH}$ decreased $\mathrm{W} / \mathrm{H}$ ratio in three of the five studies that report this parameter, but this was not confirmed in two other studies. RhGH increased LBM by $2-5 \%$ and decreased fat mass by $7-10 \%(12,14,16)$ in four studies $(n=192)(11,12,14,16)$, but this was not confirmed in two other studies $(n=35)(23,24)$. One study documented that these positive effects of rhGH on $\mathrm{BC}$ were reversed when rhGH therapy was subsequently stopped, even after only 3 months $(n=12)$ (14). Therefore, there are undeniable effects of rhGH substitution in elderly subjects with GHD for some, but not all, parameters.

Several animal models of GHD show prolonged, rather than decreased, longevity. Mice with mutations that cause GHD or GH resistance live longer than their genetically normal siblings (9, 36-39). In addition, adult body size, which can be considered a biological outcome marker of GH actions, was negatively correlated with longevity in other species, including rats (40), horses (41) and domestic dogs $(42,43)$. Therefore, from an evolutionary perspective, the natural decrease of GH and IGF1 levels during normal aging may even be beneficial. Epidemiological studies in humans, however, documented an association between both decreased and increased IGF1 levels and increased mortality, indicating that the optimal relation between IGF1 and rhGH dose may not be simple $(9,44)$. Accordingly, it is presently not straightforward that all elderly subjects with GHD should be treated unconditionally.

In conclusion, only a small number of randomized placebo controlled trials have assessed the beneficial effects of rhGH therapy in the elderly. These studies show relatively limited effects. Therefore, the question remains whether the treatment with rhGH is clinically relevant in elderly, and especially very old, patients with GHD.

\section{Declaration of interest}

The authors declare that there is no conflict of interest that could be perceived as prejudicing the impartiality of the research reported. 


\section{Funding}

This research did not receive any specific grant from any funding agency in the public, commercial or not-for-profit sector.

\section{Acknowledgements}

We gratefully acknowledge J W Schoones for all his help concerning the literature search.

\section{References}

1 Corpas E, Harman SM \& Blackman MR. Human growth hormone and human aging. Endocrine Reviews 199314 20-39. (doi:10. 1210/edrv-14-1-20)

2 Arvat E, Giordano R, Gianotti L, Broglio F, Camanni F \& Ghigo E. Neuroendocrinology of the human growth hormone-insulinlike growth factor I axis during ageing. Growth Hormone and IGF Research 19999 111-115. (doi:10.1016/S1096-6374(99) 80022-7)

3 de Boer H, Blok GJ \& Van der Veen AE. Clinical aspects of growth hormone deficiency in adults. Endocrine Reviews 199516 63-86. (doi:10.1210/edrv-16-1-63)

4 Liu H, Bravata DM, Olkin I, Nayak S, Roberts B, Garber AM \& Hoffman AR. Systematic review: the safety and efficacy of growth hormone in the healthy elderly. Annals of Internal Medicine 2007 $146104-115$.

5 Rudman D, Feller AG, Nagraj HS, Gergans GA, Lalitha PY, Goldberg AF, Schlenker RA, Cohn L, Rudman IW \& Mattson DE. Effects of human growth hormone in men over 60 years old. New England Journal of Medicine 1990323 1-6. (doi:10.1056/ NEJM199007053230101)

6 Papadakis MA, Grady D, Black D, Tierney MJ, Gooding GA, Schambelan M \& Grunfeld C. Growth hormone replacement in healthy older men improves body composition but not functional ability. Annals of Internal Medicine $1996 \mathbf{1 2 4} 708-716$.

7 Johannsson G, Marin P, Lonn L, Ottosson M, Stenlöf K, Björntorp P. Sjöström L \& Bengtsson BA. Growth hormone treatment of abdominally obese men reduces abdominal fat mass, improves glucose and lipoprotein metabolism, and reduces diastolic blood pressure. Journal of Clinical Endocrinology and Metabolism 199782 727-734. (doi:10.1210/jc.82.3.727)

8 Franco C, Brandberg J, Lonn L, Andersson B, Bengtsson BA \& Johannsson G. Growth hormone treatment reduces abdominal visceral fat in postmenopausal women with abdominal obesity: a 12-month placebo-controlled trial. Journal of Clinical Endocrinology and Metabolism 200590 1466-1474. (doi:10.1210/jc.20041657)

9 van Bunderen CC, van Nieuwpoort I, van Schoor NM, Deeg DJ, Lips $\mathrm{P} \&$ Drent ML. The association of serum insulin-like growth factor-I with mortality, cardiovascular disease, and cancer in the elderly: a population-based study. Journal of Clinical Endocrinology and Metabolism 2010 95 4616-4624. (doi:10. 1210/jc.2010-0940)

10 Koltowska-Haggstrom M, Mattsson AF \& Shalet SM. Assessment of quality of life in adult patients with GH deficiency: KIMS contribution to clinical practice and pharmacoeconomic evaluations. European Journal of Endocrinology 2009161 (Supplement 1) S51-S64. (doi:10.1530/EJE-09-0266)

11 Feldt-Rasmussen U, Wilton P \& Jonsson P. Aspects of growth hormone deficiency and replacement in elderly hypopituitary adults. Growth Hormone and IGF Research 200414 (Supplement A) S51-S58. (doi:10.1016/j.ghir.2004.03.013)

12 Gotherstrom G, Elbornsson M, Stibrant-Sunnerhagen K, Bengtsson BA, Johannsson G \& Svensson J. Muscle strength in elderly adults with GH deficiency after 10 years of GH replacement. European Journal of Endocrinology 2010163 207-215. (doi:10. 1530/EJE-10-0009)
13 Fernholm R, Bramnert M, Hagg E, Hilding A, Baylink DJ, Mohan S \& Thorén M. Growth hormone replacement therapy improves body composition and increases bone metabolism in elderly patients with pituitary disease. Journal of Clinical Endocrinology and Metabolism 2000 85 4104-4112. (doi:10.1210/jc.85.11. 4104)

14 Gill MS, Toogood AA, Jones J, Clayton PE \& Shalet SM. Serum leptin response to the acute and chronic administration of growth hormone $(\mathrm{GH})$ to elderly subjects with GH deficiency. Journal of Clinical Endocrinology and Metabolism $1999 \mathbf{8 4}$ 1288-1295. (doi:10.1210/jc.84.4.1288)

15 Monson JP, Abs R, Bengtsson BA, Bennmarker H, FeldtRasmussen U, Hernberg-Stâhl E, Thorén M, Westberg B, Wilton $\mathrm{P} \&$ Wüster C. Growth hormone deficiency and replacement in elderly hypopituitary adults. KIMS Study Group and the KIMS International Board. Pharmacia and Upjohn International Metabolic Database. Clinical Endocrinology 2000 53 281-289. (doi:10.1046/j.1365-2265.2000.01104.x)

16 Elgzyri T, Castenfors J, Hagg E, Backman C, Thoren M \& Bramnert M. The effects of GH replacement therapy on cardiac morphology and function, exercise capacity and serum lipids in elderly patients with GH deficiency. Clinical Endocrinology 200461 113-122. (doi:10.1111/j.1365-2265.2004.02080.x)

17 Sathiavageeswaran M, Burman P, Lawrence D, Harris AG, Falleti MG, Maruff P \& Wass J. Effects of GH on cognitive function in elderly patients with adult-onset GH deficiency: a placebocontrolled 12-month study. European Journal of Endocrinology 2007 156 439-447. (doi:10.1530/eje.1.02346)

18 Ho KK. Consensus guidelines for the diagnosis and treatment of adults with GH deficiency II: a statement of the GH research society in association with the European Society for Pediatric Endocrinology, Lawson Wilkins Society, European Society of Endocrinology, Japan Endocrine Society, and Endocrine Society of Australia. European Journal of Endocrinology 2007157 695-700. (doi:10.1530/EJE-07-0631)

19 Gotherstrom G, Bengtsson BA, Sunnerhagen KS, Johannsson G \& Svensson J. The effects of five-year growth hormone replacement therapy on muscle strength in elderly hypopituitary patients. Clinical Endocrinology 200562 105-113. (doi:10.1111/j.13652265.2004.02181.x)

20 Toogood AA \& Shalet SM. Growth hormone replacement therapy in the elderly with hypothalamic-pituitary disease: a dose-finding study. Journal of Clinical Endocrinology and Metabolism $1999 \mathbf{8 4}$ 131-136. (doi:10.1210/jc.84.1.131)

21 Monson JP \& Jonsson P. Aspects of growth hormone (GH) replacement in elderly patients with $\mathrm{GH}$ deficiency: data from KIMS. Hormone Research 200360 112-120. (doi:10.1159/ $000071235)$

22 White HD, Ahmad AM, Durham BH, Patwala A, Whittingham P, Fraser WD \& Vora JP. Growth hormone replacement is important for the restoration of parathyroid hormone sensitivity and improvement in bone metabolism in older adult growth hormone-deficient patients. Journal of Clinical Endocrinology and Metabolism 200590 3371-3380. (doi:10.1210/jc.2004-1650)

23 Franco C, Johannsson G, Bengtsson BA \& Svensson J. Baseline characteristics and effects of growth hormone therapy over two years in younger and elderly adults with adult onset GH deficiency. Journal of Clinical Endocrinology and Metabolism $2006914408-4414$. (doi:10.1210/jc.2006-0887)

24 De Marinis L, Mancini A, Giampietro A, Gentilella R, Bianchi A, Perrelli M, Vezzosi C, Milardi D, Fusco A, Valle D \& Bernabei R. GH deficiency syndrome in elderly patients. Journal of Endocrinological Investigation 200225 40-41.

25 Landin-Wilhelmsen K, Wilhelmsen L, Lappas G, Rosen T, Lindstedt G, Lundberg PA, Rosén T, Lindstedt G, Lundberg PA \& Bengtsson BA. Serum insulin-like growth factor I in a random population sample of men and women: relation to age, sex, smoking habits, coffee consumption and physical activity, blood pressure and concentrations of plasma lipids, fibrinogen, parathyroid hormone and osteocalcin. Clinical Endocrinology 199441 351-357. (doi:10.1111/j.1365-2265.1994.tb02556.x) 
26 Drake WM, Coyte D, Camacho-Hübner C, Jivanji NM, Kaltsas G, Wood DF, Trainer PJ, Grossman AB, Besser GM \& Monson JP. Optimizing growth hormone replacement therapy by dose titration in hypopituitary adults. Journal of Clinical Endocrinology and Metabolism $1998 \quad 83$ 3913-3919. (doi:10. 1210/jc.83.11.3913)

27 Janssen YJ, Frolich M \& Roelfsema F. A low starting dose of genotropin in growth hormone-deficient adults. Journal of Clinical Endocrinology and Metabolism 199782 129-135. (doi:10.1210/ jc.82.1.129)

28 Hilding A, Hall K, Wivall-Helleryd IL, Saaf M, Melin AL \& Thoren M. Serum levels of insulin-like growth factor I in 152 patients with growth hormone deficiency, aged 19-82 years, in relation to those in healthy subjects. Journal of Clinical Endocrinology and Metabolism 199984 2013-2019. (doi:10. 1210/jc.84.6.2013)

29 Bruce A, Andersson M, Arvidsson B \& Isaksson B. Body composition. Prediction of normal body potassium, body water and body fat in adults on the basis of body height, body weight and age. Scandinavian Journal of Clinical and Laboratory Investigation 198040 461-473. (doi:10.3109/00365518009101869)

30 Finucane FM, Liew A, Thornton E, Rogers B, Tormey W \& Agha A. Clinical insights into the safety and utility of the insulin tolerance test (ITT) in the assessment of the hypothalamo-pituitary-adrenal axis. Clinical Endocrinology 200869 603-607. (doi:10.1111/ j.1365-2265.2008.03240.x)

31 Eskes SA, Tomasoa NB, Endert E, Geskus RB, Fliers E \& Wiersinga WM. Establishment of reference values for endocrine tests. Part VII: growth hormone deficiency. Netherlands Journal of Medicine 200967 127-133.

32 Toogood AA, Jones J, O'Neill PA, Thorner MO \& Shalet SM. The diagnosis of severe growth hormone deficiency in elderly patients with hypothalamic-pituitary disease. Clinical Endocrinology 1998 48 569-576. (doi:10.1046/j.1365-2265.1998.00440.x)

33 Ghigo E, Goffi S, Nicolosi M, Arvat E, Valente F, Mazza E, Ghigo MC \& Camanni F. Growth hormone $(\mathrm{GH})$ responsiveness to combined administration of arginine and GH-releasing hormone does not vary with age in man. Journal of Clinical Endocrinology and Metabolism 199071 1481-1485. (doi:10.1210/ jcem-71-6-1481)

34 Colao A, Di SC, Savastano S, Rota F, Savanelli MC, Aimaretti G \& Lombardi G. A reappraisal of diagnosing GH deficiency in adults: role of gender, age, waist circumference, and body mass index. Journal of Clinical Endocrinology and Metabolism $2009 \mathbf{9 4}$ 4414-4422. (doi:10.1210/jc.2009-1134)

35 Packard CJ, Ford I, Robertson M, Shepherd J, Blauw GJ, Murphy MB, Bollen EL, Buckley BM, Cobbe SM, Gaw A, Hyland M, Jukema JW, Kamper AM, Macfarlane PW, Perry IJ,
Stott DJ, Sweeney BJ, Twomey C \& Westendorp RG; PROSPER Study Group. Plasma lipoproteins and apolipoproteins as predictors of cardiovascular risk and treatment benefit in the PROspective Study of Pravastatin in the Elderly at Risk (PROSPER). Circulation 2005112 3058-3065. (doi:10.1161/CIRCULATIONAHA.104.526848)

36 Bartke A \& Brown-Borg H. Life extension in the dwarf mouse. Current Topics in Developmental Biology 200463 189-225. (doi:10.1016/S0070-2153(04)63006-7)

37 Bartke A. Growth hormone and aging: a challenging controversy. Clinical Interventions in Aging 20083 659-665. (doi:10.2147/ CIA.S3697)

38 Bonkowski MS, Pamenter RW, Rocha JS, Masternak MM, Panici JA \& Bartke A. Long-lived growth hormone receptor knockout mice show a delay in age-related changes of body composition and bone characteristics. Journals of Gerontology. Series A, Biological Sciences and Medical Sciences $2006 \mathbf{6 1} 562-567$.

39 Coschigano KT, Holland AN, Riders ME, List EO, Flyvbjerg A \& Kopchick JJ. Deletion, but not antagonism, of the mouse growth hormone receptor results in severely decreased body weights, insulin, and insulin-like growth factor I levels and increased life span. Endocrinology $2003 \mathbf{1 4 4} 3799-3810$. (doi:10.1210/en. 2003-0374)

40 Rollo CD. Growth negatively impacts the life span of mammals. Evolution and Development 20024 55-61. (doi:10.1046/j.1525142x.2002.01053.x)

41 Brosnahan MM \& Paradis MR. Assessment of clinical characteristics, management practices, and activities of geriatric horses. Journal of American Veterinary Medical Association 2003223 99-103. (doi:10. 2460/javma.2003.223.99)

42 Greer KA, Canterberry SC \& Murphy KE. Statistical analysis regarding the effects of height and weight on life span of the domestic dog. Research in Veterinary Science 200782 208-214. (doi:10.1016/j.rvsc.2006.06.005)

43 Patronek GJ, Waters DJ \& Glickman LT. Comparative longevity of pet dogs and humans: implications for gerontology research. Journals of Gerontology. Series A, Biological Sciences and Medical Sciences 199752 B171-B178. (doi:10.1093/gerona/52A.3. B171)

44 Dekkers OM, Biermasz NR, Pereira AM, Romijn JA \& Vandenbroucke JP. Mortality in acromegaly: a metaanalysis. Journal of Clinical Endocrinology and Metabolism 200893 61-67. (doi:10.1210/jc.2007-1191)

Received 2 February 2011

Accepted 20 February 2011 